\title{
Correction to: Weather patterns and all-cause mortality in England, UK
}

\author{
Kyriaki Psistaki ${ }^{1}$ - Anastasia K. Paschalidou ${ }^{1}$ - Glenn McGregor ${ }^{2}$
}

Published online: 12 December 2019

(C) ISB 2019

\section{Correction to: International Journal of Biometeorology https://doi.org/10.1007/s00484-019-01803-0}

The original article was published with an erroneous rendering of Eq. 2 in the article's Methodology section. Provided is the correct rendering of this equation:

$P I_{i}=100 \times\left(\frac{\text { Number of deaths in } C_{i} / \text { Total Number of Deaths }}{\text { Number of days in } C_{i} / \text { Total Number of Days }}-1\right)$

where $C_{i}$ stands for the different weather types.

This correction stands to correct the original article. The original article has been corrected.

Publisher's Note Springer Nature remains neutral with regard to jurisdictional claims in published maps and institutional affiliations.

The online version of the original article can be found at https://doi.org/ 10.1007/s00484-019-01803-0

Anastasia K. Paschalidou

apascha@fmenr.duth.gr

1 Department of Forestry and Management of the Environment and

Natural Resources, Democritus University of Thrace,

Orestiada, Greece

2 Department of Geography, Durham University, Durham, UK 